\title{
Combined Rupture of Vaginal Vault and Unscarred Uterus and Neonatal Death Following Induction of Labor with Misoprostol
}

\author{
J. Darido ${ }^{1,2}$, J. Khazaal1,2, Z. Bazzi ${ }^{1,2}$, R. Chahine ${ }^{1,3}$, W. Moustafa',2, M. K. Ramadan ${ }^{1,2}$ \\ ${ }^{1}$ Department of Obstetrics and Gynecology, Rafic Hariri University Hospital, Beirut, Lebanon \\ ${ }^{2}$ Department of Obstetrics and Gynecology, Lebanese University, Beirut, Lebanon \\ ${ }^{3}$ Clinical Associate, American University of Beirut-Medical Center, Beirut, Lebanon \\ Email: *jesydarido@hotmail.com
}

How to cite this paper: Darido, J., Khazaal, J., Bazzi, Z., Chahine, R., Moustafa, W. and Ramadan, M.K. (2019) Combined Rupture of Vaginal Vault and Unscarred Uterus and Neonatal Death Following Induction of Labor with Misoprostol. Open Journal of Obstetrics and Gynecology, 9, 643-648. https://doi.org/10.4236/ojog.2019.95063

Received: April 14, 2019

Accepted: May 17, 2019

Published: May 20, 2019

Copyright $\odot 2019$ by author(s) and Scientific Research Publishing Inc. This work is licensed under the Creative Commons Attribution International License (CC BY 4.0).

http://creativecommons.org/licenses/by/4.0/

\begin{abstract}
Introduction: Rupture of unscarred uterus (primary uterine rupture) is a rare peripartum complication often associated with catastrophic maternal and neonatal outcomes. Case presentation: A 27-year-old primigravid lady, previously healthy, at 40 weeks +2 days presented to a midwife's clinic for routine antenatal consultation. She was advised to have induction of labor. This was initiated with 2 tablets of Misoprostol (400 mcg) vaginally. Twelve hours later, and after remaining at full cervical dilation for 4 hours, she was referred to our maternity service for alleged failure to descend. On arrival, she was apprehensive, exhausted but hemodynamically stable. Pelvic exam disclosed a fully dilated cervix with the vertex at $S+1$ and a caput reaching the introitus. No fetal heart rate could be elicited by the CTG monitor and this was verified by a bedside ultrasonography. Operative vaginal delivery was performed due to maternal exhaustion. This was complicated by transient shoulder dystocia. Manual revision of the birth canal and the uterine cavity disclosed a suspicion of left vaginal vault gapping together with a left fundal uterine rupture. Consequently, the patient was rushed to the operating room for an urgent exploratory laparotomy. The rupture sites were identified and repaired while a large broad ligament hematoma on the same side was explored and hemostasis secured with ipsilateral uterine artery ligation of the fundal and cervical branches. The postoperative course was smooth and the patient left the hospital on the $5^{\text {th }}$ day postpartum. Conclusion: Cases of unscarred uterine rupture are limited. One of the most frequent risk factor is the injudicious use of Misoprostol for labor induction. Sudden arrest of progress of labor or failure to descend might mask uterine rupture. We recommend that all birth attendants be familiar with the guidelines issued by FIGO, ACOG and other societies for the safe use of these potent uterotonics.
\end{abstract}




\section{Keywords}

Rupture of Unscarred Uterus, Misoprostol, Induction of Labor

\section{Introduction}

Before 1960, when the rate of cesarean delivery was relatively low and the rate of grand multiparity was comparatively higher, rupture of unscarred uterus, also termed primary uterine rupture, predominated over secondary uterine rupture [1].

Due to its rarity, there is a paucity of published cases. Its incidence appears to be somewhere between $1 / 5700$ and 1/20,000 [2] [3], and currently, it seems to account for $13 \%$ of all uterine ruptures [4].

Hereby, we report a case of combined rupture of unscarred gravid uterus and the vaginal vault after induction of labor with Misoprostol in a primigravid lady.

Note that an informed consent was obtained was obtained from the patient to report this case.

\section{CASE Description}

A 27 -year-old primigravid lady, at 40 weeks +2 days, previously healthy with non-significant past surgical or medical history, presented to a midwife's clinic for routine antenatal consultation. She was advised to have induction of labor which was initiated with 2 tablets of vaginal Misoprostol $(400 \mathrm{mcg}$ ). Twelve hours later, and after remaining at full cervical dilation for 4 hours, she was referred to our maternity service for alleged failure to descend. To note, that the patient was not well followed during her current pregnancy. She was transferred from the midwife's clinic with a medical report featuring non-reassuring fetal heart rate. Upon questioning the patient, she revealed seeing a midwife earlier during the day who gave her 2 vaginal tabs of Misoprostol $200 \mathrm{mcg}$ each for labor induction then she was sent home. Shortly after arriving home, she developed acute onset of labor pain associated with vaginal bleeding.

Upon presentation to labor and delivery unit at Rafic Hariri University Hospital, the patient looked apprehensive, exhausted but hemodynamically stable. Pelvic exam revealed fully dilated cervix, cephalic presentation, Station +1 ; fetal heart rate could not be detected on monitor. Bedside ultrasound confirmed negative fetal heart activity.

After pushing to +2 station, maternal exhaustion was noted. After a mediolateral episiotomy, an operative vaginal delivery was done with a vacuum but complicated by transient shoulder dystocia for less than 1 minute, APGAR score were $0 / 0$ at 1 minute then 5 minutes respectively and the baby was transferred to the morgue.

A gush of considerable amount of brownish blood was noted following the delivery of the incomplete placenta. A manual revision of the birth canal and 
uterine cavity was done where a gap in the left lateral fornix was felt and another tear in the left mid portion of the uterus was felt leading into the adjacent broad ligament. Uterine and vaginal vault ruptures were highly suspected. Consequently, the patient was rushed to the operating room immediately for an exploratory laparotomy.

Under general anesthesia, and the patient in dorsal lithotomy position, scrubbed and draped properly. Entry of the abdomen was done via a midline incision and an estimated $500 \mathrm{cc}$ of free intraperitoneal blood was noted. Bladder flap was created. Uterus was exteriorized and a large hematoma was noted extending from the left uterine cornua down to the uterine isthmus. Another rent was noted also communicating the broad ligament space into the upper vagina (Figure 1). These were properly repaired in layers to restore anatomy. Hemostasis was secured through placing two separate sutures to the ascending and descending branches of the uterine artery. The retroperitoneal dissection was done to identify the ureter course prior to suturing. A large "Hemovac" drain was placed in the peritoneal cavity.

Patient received 1 unit of packed red blood cells in the operating room and was transferred to the recovery area in a stable condition.

At day 0 , the patient was clinically and hemodynamically stable. Hemovac drained $100 \mathrm{cc} / 12 \mathrm{~h}$ of serosanguinous fluid, Hemoglobin 11 (baseline of 14). She was afebrile on Amoxicillin/Clavulanate $1.2 \mathrm{~g} \mathrm{q} 8 \mathrm{~h}$.

At day 5, the patient voided freely and before discharge she was counseled about possible future uterine rupture risks and advised for elective cesarean delivery before 36 weeks gestation.

\section{Discussion}

In comparison with a scarred uterus, a rupture of an unscarred uterus is associated with higher maternal and neonatal morbidity. Women were found to be at increased risk for blood transfusion, ICU admissions and longer hospital stay, whereas, newborns had higher mortality or poor condition at discharge [5]. This poor outcome was also confirmed by others who noted increased peripartum hysterectomy, neonatal intensive care unit admission and hypoxic ischemic encephalopathy in unscarred vs. scarred uteri [6] [7]. Nevertheless, time to delivery $>30$ minutes and placental separation and/or fetal extrusion had the highest association with intrapartum/infant deaths after complete uterine rupture. Whether these events occur more in unscarred uterus is not clear. Time to delivery $<20$ minutes limited the incidence of intrapartum/infant deaths [7]. It seems that close monitoring and the care provided for parturients with scarred uterus plays a role in initiating early intervention as reflected by better maternal and neonatal outcomes.

The two main etiologies commonly reported were: 1) Trauma of any kind [1] [6], motor vehicle accidents, intrapartum suprafundic pressure, operative vaginal delivery [3]. 2) Weakened myometrium due to either a congenital pathology 


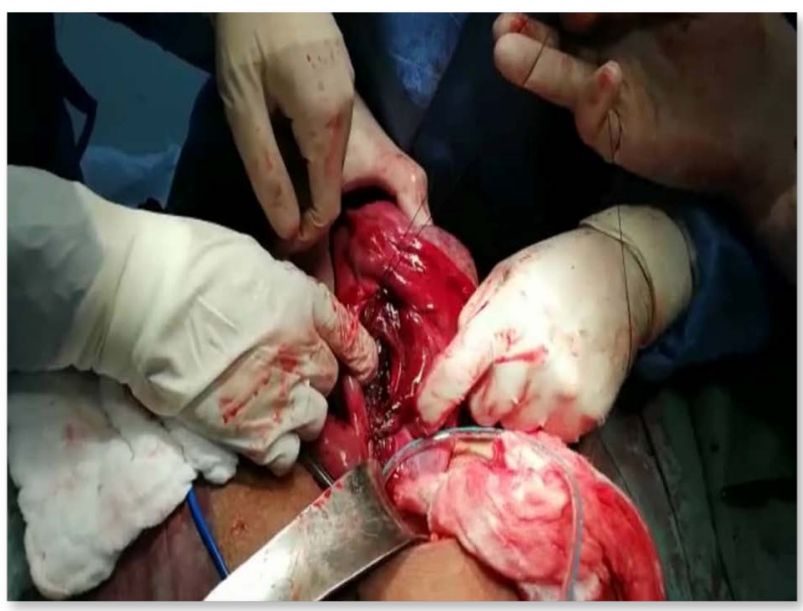

Figure 1. Intraoperative appearance of the uterine lateral wall rupture.

such as Mullarian anomalies, or a congenital defect in collagen like that seen in Marfan syndrome and Ehler-Danlos syndrome; or an acquired myometrial defect due to any of the following: high parity, exposure to uterotonic drugs, uterine anomalies, advanced maternal age, dystocia, macrosomia, multiple gestation and abnormal placentation (PAS) [1] [7].

Most reported cases of uterine rupture typically involved patients with more than one risk factor [8] [9], unlike our patient who had only one risk factor, namely the exposure to a strong uterotonic drug. Al-Zirqi et al., in 2016, concluded that a major risk factor for complete uterine rupture in intact and scarred uteri was the sequential labor induction with prostaglandins and oxytocin, compared to spontaneous labor [7]. Other significant risk factors include labor augmentation with oxytocin, antepartum fetal death and previous first-trimester miscarriages [10].

In our case, the adverse event of uterine rupture occurred mainly because Misoprostol was used in high dose and uterine activity was not properly monitored.

Uterine activity and fetal status should have been carefully monitored and preferably in a hospital setting. The guidelines related to the practice of induction of labor issued by WHO states clearly that women receiving Misoprostol or similar Prostaglandins should never been left unattended. Recent Cochrane reviews demanded the following: owing to concerns about the risk of uterine hyperstimulation with vaginal Misoprostol, ripening of cervix with lower vaginal Misoprostol doses or resorting to oral route of administration [11] [12] [13]. Doses limited to 25 or $50 \mathrm{mcg}$ should have been used only which makes $1 / 8^{\text {th }}-1 / 16^{\text {th }}$ of the total dose received by this patient. Interestingly, the administration of this drug for cervical ripening and labor induction is considered an off-label use by the FDA in the United States. Nevertheless, The American College of Obstetricians and Gynecologists (ACOG) has stated that the use of Misoprostol appears as safe and efficacious as other prostaglandin agents when used as a cervical ripening and/or labor induction agent [14], hence, the use of Misoprostol for augmentation of labor is not advised and this could have been 
replaced by Oxytocin for this purpose. This does not imply that Oxytocin is completely safe and without problems. There are also strict guidelines governing it judicious use for initiation and augmentation of labor. Its use requires close monitoring and vast experience as well.

Clinical presentation of unscarred uterine rupture is similar to that of a scarred uterus, but usually more vigilance accompanies laboring women with scarred uteri while diagnosis is comparatively delayed in rupture of unscarred ones. Our patient had vaginal bleeding which is mostly seen with rupture of the anterior lower segment, whereas usually rupture of the uterine fundus or posterior wall could be concealed.

Our main differential diagnosis in this case was placental abruption, which was immediately ruled out by postpartum examination of the placenta.

The risk of rupture in future pregnancies ranges between $22 \%$ and $100 \%$ [15], accordingly, she was counseled that elective cesarean delivery should be performed not later than 36 completed weeks gestation [16].

\section{Conclusion}

Most data related to uterine rupture are derived from studies on scarred uteri. The reported cases of rupture of unscarred uterus are limited possibly due to underreporting. Limited data is available on maternal and newborn outcome. Furthermore, our knowledge about the risk factors and the incidence is derived from case reports or small series. Nevertheless, all birth attendants practicing in small maternities, private birthing clinics or performing home birthing should be familiar with the appropriate use of all uterotonic medications, especially prostaglandins to ensure patient and newborn safety.

\section{Conflicts of Interest}

The authors declare no conflicts of interest regarding the publication of this paper.

\section{References}

[1] Cunningham, F.G., Leveno, K.J., Bloom, S.L., Spong, K.Y., Dash, J.S., Hoffman, B.L., et al. (2014) Abortion. In: Cunningham, F.G., Leveno, K.J., Bloom, S.L., Spong, K.Y., Dash, J.S., Hoffman, B.L., et al., Eds., Williams Obstetrics, 24th Edition, McGraw Hill Education, New York, 291-292.

[2] Dow, M., Wax, J.R., Pinette, M.G., Blackstone, J. and Cartin, A. (2009) Third-Trimester Uterine Rupture without Previous Cesarean: A Case Series and Review of the Literature. American Journal of Perinatology, 26, 739-744. https://doi.org/10.1055/s-0029-1223287

[3] Miller, D.A., Goodwin, T.M., Gherman, R.B. and Paul, R.H. (1997) Intrapartum Rupture of Unscarred Uterus. Obstetrics \& Gynecology, 89, 671-673. https://doi.org/10.1016/S0029-7844(97)00073-2

[4] Zwart, J.J., Richters, J.M., Ory, F., de Vries, J.I., Bloemenkamp, K.W. and van Roosmalen, J. (2009) Uterine Rupture in the Netherlands: A Nationwide Population-Based Cohort Study, BJOG, 116, 1069-1078. 
https://doi.org/10.1111/j.1471-0528.2009.02136.x

[5] Barger, M.K., Nannini, A., DeJoy, S., Wisner, K. and Markenson, G. (2013) Maternal and Newborn Outcomes Following Uterine Rupture among Women without versus Those with a Prior Cesarean. The Journal of Maternal-Fetal \& Neonatal Medicine, 26, 183-187. https://doi.org/10.3109/14767058.2012.725790

[6] Gibbins, K.J., Weber, T., Holmgren, C.M., Porter, T.F., Varner, M.W. and Manuck, T.A. (2015) Maternal and Fetal Morbidity Associated with Uterine Rupture of the Unscarred Uterus. American Journal of Obstetrics \& Gynecology, 213, 382.e1-e6. https://doi.org/10.1016/j.ajog.2015.05.048

[7] Al-Zirqi, I., Daltveit, A.K. and Vangen, S. (2018) Infant Outcome after Complete Uterine Rupture. American Journal of Obstetrics and Gynecology, 219, 109.e1-e8. https://doi.org/10.1016/j.ajog.2018.04.010

[8] Noh, J.J., Park, C.H., Jo, M.H. and Kwon, J.Y. (2013) Rupture of an Unscarred Uterus in a Woman with Long-Term Steroid Treatment for Systemic Lupus Erythematosus. Obstetrics \& Gynecology, 122, 472-475.

https://doi.org/10.1097/AOG.0b013e3182998fb6

[9] Palmer, J.M., Indermaur, M.D., Tebes, C.C. and Spellacy, W.N. (2008) Placenta Increta and Cocaine Abuse in a Grand Multipara Leading to a Second Trimester Rupture of an Unscarred Uterus: A Case Report. The Southern Medical Journal, 101, 834. https://doi.org/10.1097/SMJ.0b013e31817f1f44

[10] Al-Zirqi, I., Daltveit, A.K., Forsén, L., Stray-Pedersen, B. and Vangen, S. (2017) Risk Factors for Complete Uterine Rupture. American Journal of Obstetrics and Gynecology, 216, 165.e1-8. https://doi.org/10.1016/j.ajog.2016.10.017

[11] Hofmeyr, G.J., Gülmezoglu, A.M. and Pileggi, C. (2010) Vaginal Misoprostol for Cervical Ripening and Induction of Labour. Cochrane Database of Systematic Reviews, No. 10, CD000941. https://doi.org/10.1002/14651858.CD000941.pub2

[12] Alfirevic, Z. and Weeks, A. (2006) Oral Misoprostol for Induction of Labour. Cochrane Database of Systematic Reviews, No. 2, D001338. https://doi.org/10.1002/14651858.CD001338.pub2

[13] Muzonzini, G. and Hofmeyr, G.J. (2004) Buccal or Sublingual Misoprostol for Cervical Ripening and Induction of Labour. Cochrane Database of Systematic Reviews, No. 4, D004221. https://doi.org/10.1002/14651858.CD004221.pub2

[14] ACOG Committee on Practice Bulletins-Obstetrics (2009) ACOG Practice Bulletin No. 107: Induction of Labor. Obstetrics \& Gynecology, 114, 386-397. https://doi.org/10.1097/AOG.0b013e3181b48ef5

[15] Chibber, R., El-Saleh, E., Al Fadhli, R., Al Jassar, W. and Al Harmi, J. (2010) Uterine Rupture and Subsequent Pregnancy Outcome-How Safe Is It? A 25-Year Study. The Journal of Maternal-Fetal \& Neonatal Medicine, 23, 421-424. https://doi.org/10.3109/14767050903440489

[16] ACOG (2019) ACOG Committee Opinion No. 764: Medically Indicated Late-Preterm and Early-Term Deliveries. Obstetrics \& Gynecology, 133, e151-e155.

https://doi.org/10.1097/AOG.0000000000003083 